\title{
High Temperature Spectral Gamma Well Logging
}

\author{
Randy A. Normann and Joseph A. Henfling \\ Sandia National Laboratories, Albuquerque \\ CONF-971048- - 2
}

\begin{abstract}
A high temperature spectral gamma tool has been designed and built for use in small-diameter geothermal exploration wells. Several engineering judgments are discussed regarding operating parameters, well model selection, and signal processing. An actual well log at elevated temperatures is given with spectral gamma reading showing repeatability.
\end{abstract}

\section{Introduction}

Spectral gamma well logs can detect naturally occurring gamma emitting elements such as potassium, uranium, and thorium inside differing well lithologies. Potassium bearing deposits can be a byproduct of alterations. In SB-15, the spectral gamma tool measured high potassium presence in the production zone. Increased potassium maybe correlated to sericite found in fractures as seen in the core samples. Sericite contains $10 \%$ potassium by weight, $\mathrm{K}_{2} \mathrm{Al}_{4}\left[\mathrm{Si}_{6} \mathrm{Al}_{2} \mathrm{O}_{20}\right](\mathrm{OH}, \mathrm{F})_{4}$. Sericite is one example of material deposited in fractures.

A high quality spectral gamma log could, in some cases, map fractured areas. Spectral logs work with and without casing as potassium, uranium, and thorium all have gamma of sufficient energy to penetrate casing. Little is known about spectral gamma log data inside geothermal wells. There maybe correlations with uranium and thorium also.' Sandia has the only known spectral gamma tool suitable for hot well applications.

\section{Mode of Operation}

Below is a simplified block diagram of the Sandia spectral gamma tool. The tool uses a Bicron ${ }^{\text {TM }}$ MWD (Measurement-While-Drilling) thallium-activated sodium iodide crystal optically coupled to a photomultiplier. When a gamma ray hits the crystal, it surrenders some or all of its energy. The crystal produces a light (photons) proportional to the energy deposited by the incident gamma. The crystal is covered in a reflective coating with one end optically coupled to a photo-multiplier. The photo-multiplier captures the light, which causes electron flow from the high voltage supply (see Figure 1). The electron flow is also proportional to the amount of gamma ray energy deposited.

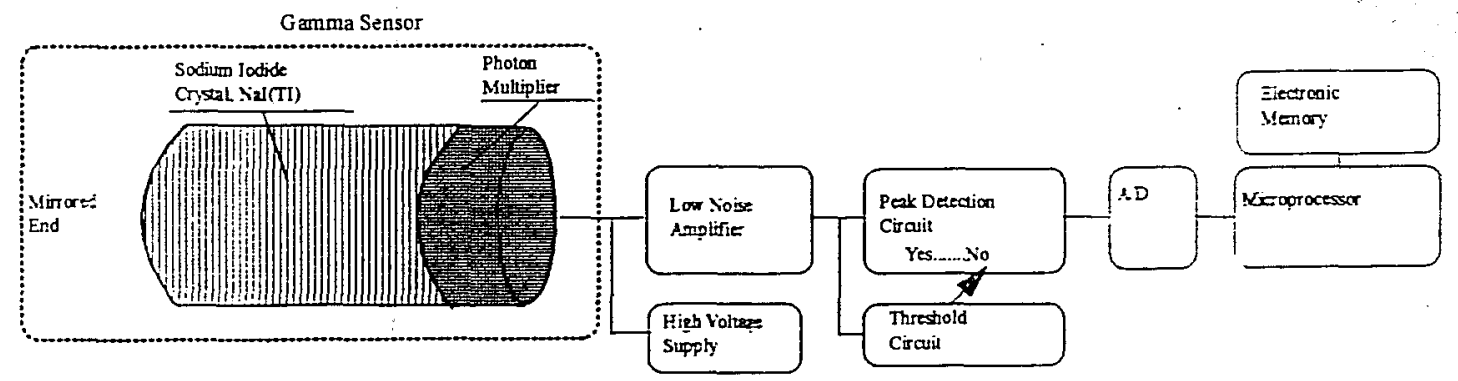

Figure 1. Simplified Block Diagram of the Sandia Spectral Gamma Logging Tool.

A low noise amplifier amplifies the small electron discharge large enough for the peak detection circuit to capture the peak signal. A threshold circuit tests the signal for sufficient amplitude. If too small, then the peak may only be electrical noise or very low energ: gamma. Once a gamma ray of sufficient energy trips the threshold circuit, the peak value is recorded. For the Sandia spectral gammainstrument the threshold 


\section{DISCLAIMER}

This report was prepared as an account of work sponsored by an agency of the United States Government. Neither the United States Government nor any agency Thereof, nor any of their employees, makes any warranty, express or implied, or assumes any legal liability or responsibility for the accuracy, completeness, or usefulness of any information, apparatus, product, or process disclosed, or represents that its use would not infringe privately owned rights. Reference herein to any specific commercial product, process, or service by trade name, trademark, manufacturer, or otherwise does not necessarily constitute or imply its endorsement, recommendation, or favoring by the United States Government or any agency thereof. The views and opinions of authors expressed herein do not necessarily state or reflect those of the United States Government or any agency thereof. 


\section{DISCLAIMER}

Portions of this document may be illegible in electronic image products. Images are produced from the best available original document. 
is predetermined at $\sim 0.35 \mathrm{MeV}$ (Million electron volts). The AND (Analog to Digital converter) then reads the peak energy value returning an eight bit binary number. The energy levels are divided into 0 to 255 channels, with channel 255 being the greatest energy level. The upper energy limit is set at $2.8 \mathrm{MeV}$. Note: A simple total count gamma tool provides a count of gamma rays above a threshold. By calibrating the total count gamma against API (American Petroleum Institute) units, the spectral gamma tool can provide both spectral gamma and conventional gamma logs.

\section{Calibration}

Gamma count rate is a relative measure of gamma flux within the well bore. This flux is proportional to the amount of radioactive material in the surrounding formation. Thus, the measured flux is converted to $\mathrm{pCi} / \mathrm{g}$ by calibration coefficients derived from tool readings within calibration models. These models have known amounts of source material distributed in a large enough volume to appear infinitely large to traveling gamma rays. Infinitely large is approximately a two foot radius from well bore center:

The most commonly used calibration models are maintained for DOE's Grand Junction Projects Office in Grand Junction, Co. This office maintains a set of field calibration models at nearby Grants. New. Mexico. These models contain three naturally occurring elements, $\mathrm{K}^{40}, \mathrm{Ra}^{226}$, and $\mathrm{Th}^{232},(\mathrm{KUT})$.

In working with subterranean gamma, there is a problem of higher energy gamma rays being counted in lower channels called down scattering. Stromswold (1981) uses gamma count windows centered about energy peaks of the three natural elements which unfold from highest energy to lowest. Table 1 shows his suggested windows.

Table 1 Spectral Energr Windows for Unfolding KUT

\section{Element}

Potassium $(\mathrm{K}-40)$

Uranium (Ra-226)

Thorium (Th-232)

\section{Unique Gamma Ray (MeV) \\ 1.46}

$1.76 \& 2.20$

2.61
Energy Window (MeV)

$1.320-1.575$

$1.6 \div 0-2.390$

$2.475-2.765$

By choosing the Thorium window about the $2.61 \mathrm{MeV}$ gamma, Thorium can be solved for because potassium and uranium don't have any gamma rays that high in energy. The uranium window centers around 1.76 and $2.20 \mathrm{MeV}$ for uranium ore excluding the potassium gamma at $1.46 \mathrm{MeV}$. Figure 2 shows the three energy windows given in Table 1 against spectrums taken at the Grents New Mexico facilities. The Grants calibration models are well suited for this unfolding process. The well model concentrations are listed' in Table 2.

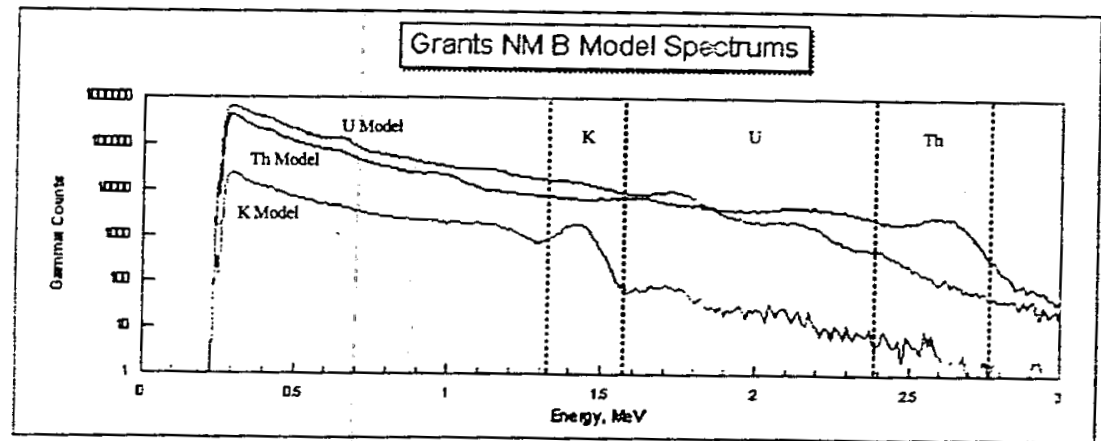

Figure 2. These are three spectral measurements made by the Sandia tool while in each of the three calibration wells at Grants, New Mexico. Sample period of one hour. 
Table 2. Grants New Mexico B-Model Concentrations

\begin{tabular}{l|ccc} 
Model & $\begin{array}{c}\text { Concentration Th } \\
(\mathrm{pCi} / \mathrm{g})\end{array}$ & $\begin{array}{c}\text { Concentration } \mathbf{U} \\
(\mathbf{p C i} / \mathrm{g})\end{array}$ & $\begin{array}{c}\text { Concentration K } \\
(\mathrm{pCi} / \mathrm{g})\end{array}$ \\
Th Model & $68.06 \pm 1.83$ & $11.34 \pm 0.58$ & $9.71 \pm 1.51$ \\
U Model & $0.71 \pm 0.06$ & $178.18 \pm 5.47$ & $11.80 \pm 0.84$ \\
K Model & $0.10 \pm 0.02$ & $1.08 \pm 0.10$ & $52.16 \pm 1.84$
\end{tabular}

By placing the spectral gamma tool into each of the three models, subtracting electrical noise, and counting gamma for each of the three windows in Table 1 , a rate matrix $R$ is produced. Matrix $R$ is guaranteed to be nonsingular because the window selection process assures an upper triangular form (an approximation, see Table 2). Using the concentrations of Table 2, a set of coefficients relating window count rates to concentrations ( $\mathrm{pCi} / \mathrm{g}$ ) can be solved for using Eql. Note: The statistical nature of gamma counting requires long counting periods to gain a meaningful count rate. The time period for Figure 2 spectrums was one hour.

$$
A=\mathrm{CR}^{-1}
$$

Where as ' $A$ ' is a $3 X 3$ matrix of calibration coefficients and $R$ is a $3 X 3$ matrix of count rate readings for each of the three windows shown in Figure 2 . ' $C$ ' is a $3 X 3$ matrix of known model concentrations from. Table 2. Once ' $A$ ' is known, the system is tested against a fourth model which is a mix of all three elements. A properly calibrated spectrometer then solves for the concentration levels in the mixed well by using Equation 2.

$$
\mathrm{C}=\mathrm{AR}
$$

Where as ' $R$ ' is a $1 X 3$ column vector containing window count readings, $[T, U, K]^{T}$ for the mixed (or unknown well) and ' $\mathrm{C}$ ' is' the resulting measured concentration of KUT for that well section in $\mathrm{pCi} / \mathrm{g}$. The measure of the gamma flux density is also dependent on well conditions such as diameter, casing. and fluid density. Also to be considered are tool electronics conversion rate and crystal size. The more complete Sandia research and development report will cover all of these topics; Expected release late summer 97.

\section{Geothermal Test Well}

This test well was the first well where Sandia's spectral tool was used and the only well that had core data. Unfortunately, only a small porion of the rell was logged due to time constraints. This section was logged three times at $2.25 \mathrm{ft} / \mathrm{min}$ and re-logged the following day at $5 \mathrm{f} / \mathrm{min}$. The slow logging rates are required to get some sense of statistical accuracy. At the time of this test, Sandia did not have a computerized depth correlation program. The data we have from this test was saved as an Excel ${ }^{\text {TMI }}$ file. The gamma readings were synchronized to depth readings manually and correlated within the Excel ${ }^{\text {TII }}$ file. The tool takes readings every ten seconds and starts when the battery is installed. There is some uncertainty as to when the battery actually makes contact to start the tool. The Sandia tools now have computerized depth and measurement time correlation, thus eliminating uncertainties.

This test well provides some of our best results. The three passes created an ensemble of data. Ensemble areraging provides the best method for gaining consistent spectral gamma well bore readings. In the filtering section, two different ensembie filters are used to filter the three passes into one well log. Rnckbusch (1983) reports that a Kalman filter design provides highly repeatable specural gamma logs. To filter spectral readings with only one pass, a Kalman filter was demonstrated. Before discussion about filtering, some basic understanding about the variance of spectral gamma well readings is needed. 


\section{Basic Understanding of Well Bore Random Variables}

As the tool moves down the well, spectral readings vary due to two random variables. First are differing rock/soil formations (lithology). As the tool moves between formations, different gamma signatures maybe expected. Because the rock formations and mineral deposits are unknown at the start of a well logging run, the desired lithology information is a random variable. However, this information does not change (quickly) with respect to time. The well information is strict sense stationary for KUT concentrations versus well depth. In the ideal case, two logging runs done on two consecutive days will have identical readings.

The second random variable is the result of natural gamma count fluctuations. The gamma measurement data is best characterized as a non-zero mean, independent, normal, random process. The valued information is the non-zero mean relating to KUT concentrations. In other words, the well bore information desired is "What would the average gamma reading be if gamma readings could be sampled for all time." Eq 3 relates the window measured counts to the formation information and noise:

$$
\mathrm{W}_{\text {Cornt }}=\mathrm{F}_{\mathrm{KUT}}+\mathrm{N}(0, \sigma)
$$

Where $W_{\text {count }}$ is the gamma count measured in any window. $F_{K U T}$ is the average count rate for any window caused by KUT formation concentrations. $\mathrm{N}$ is a normal (Gaussian) random variable with zero mean and $\sigma$ as the variance.

From these basic understandings, two assumptions can now be declared. First. ensemble averaging will eliminate zero mean noise and preserve the average $F_{K U T}$ value. Thus, multiple passes through a well section can be averaged to reduce noise. Second, two consecutive readings within a common rock/soil formation will have a common variance, $\sigma$. As with any sample system, the ability to detect changes in formation must adhere to Nyquist criteria. Thus, the best possible formation resolution is $0.75 \mathrm{ft}$ for a tool taking a reading every 10 seconds and logging at $2.25 \mathrm{ft} / \mathrm{min}$. In practice, the best resolution maybe 4 to 6 times Nyquist or 3 to $4.5 \mathrm{ft}$.

\section{Filtering the Measurement to Improve Well Readings}

\section{Unfiltered Data}

The variation of individual samples is great within a ten second counting period. Ensemble averaging is used to reduce measurement variance. Figure 3 , below is a plot of potassium nindow counts while the tool was stationary for $\sim 3$ minutes at a fixed depth of $1348.8 \mathrm{ft}$ prior to each of the three passes within the test well.

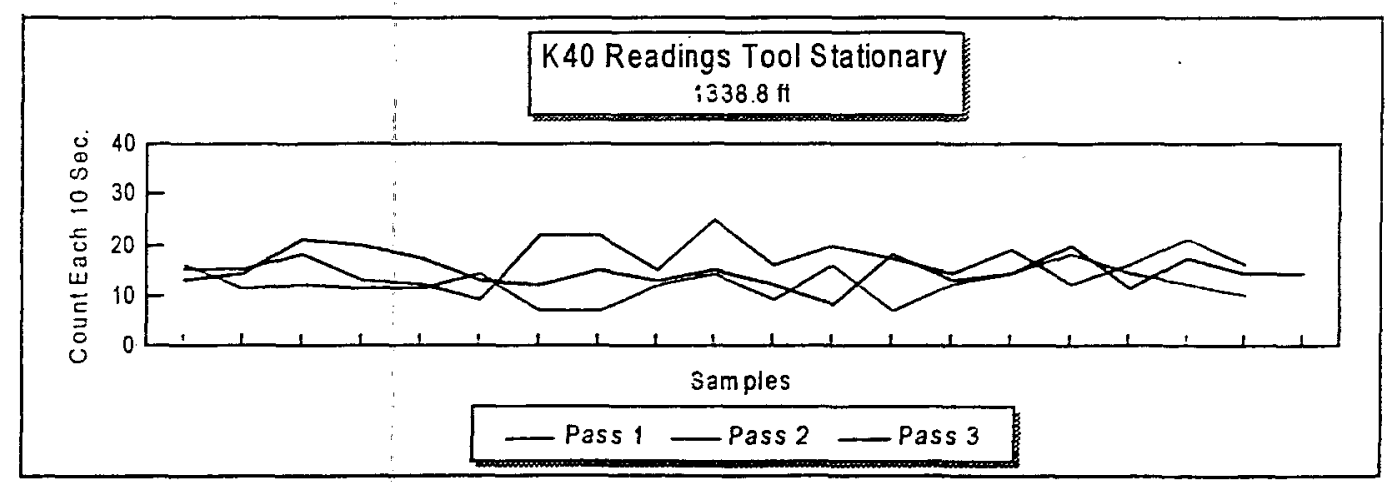

Figure 3.) Stationary readings. Note: The three stationary reads are constant at an average of 14.4 counts per period. This helps to show that the tool was not changing calibration while internal temperatures were increasing. 
The mean value for the stationary reading is 14.4 counts per 10 second reading. The standard deviation is 3.8 counts per period. The expected range of readings for three standard deviations is 3 to 26. Note: Figure 3 readings do fall within this range. Also note: The three stationary reads are constant about an average of 14.4 counts per period. This implies that the tool was not changing calibration while internal temperatures were increasing with increased well bore exposure.

Because of the large variance in count readings, some sort of smoothing must be used so that the operator can detect slight changes occurring in the average gamma counts as the tool moves past varying lithology, Figure 4 is the potassium window count plot for the three passes. It is difficult to see anything useful about this data except some increase in all three passes at $\sim 1370 \mathrm{ft}$.

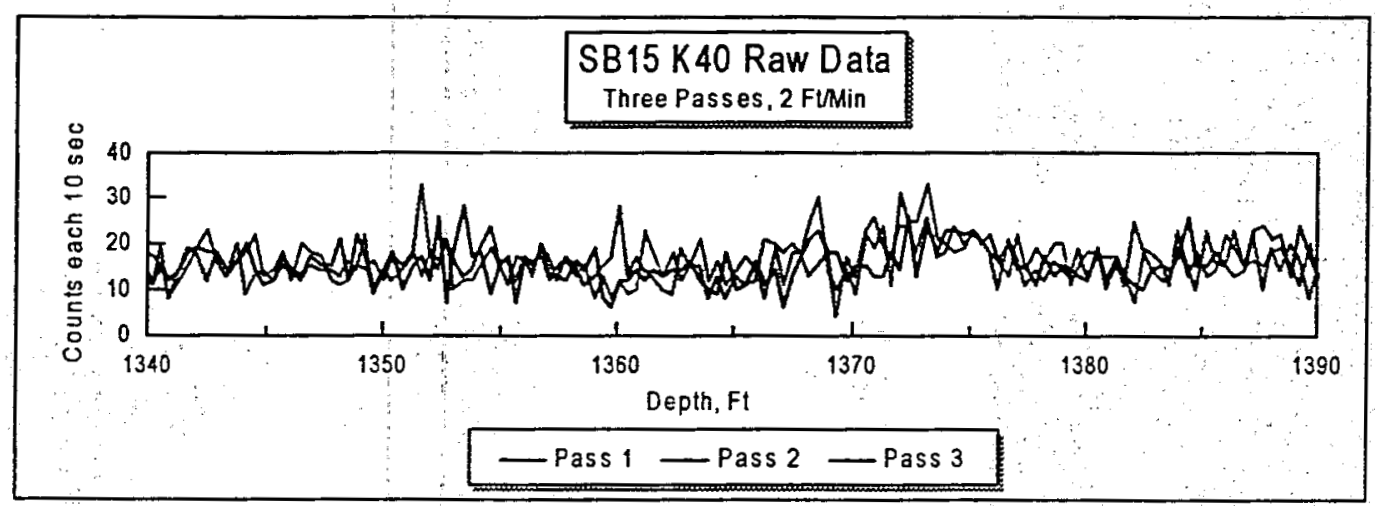

Figure 4.) Three Logs of the Same Well Section

\section{Averaging Functions}

There are a number of smoothing functions available for these problems. Linear digital filters as moving averages, FIR, IIR filters, and non-linear filters as median filters, and so on. After some experimentation, the median filter using only three points seems to provide the best overall results. Like the average value over infinite time, the median value approaches a constant value. The median value works by removing outlying sample points.

Using the stationary readings made at $1338.8 \mathrm{ft}$ shown in Figure 3 both the moving three point average and three point median values were taken. Figure 5 demonstrates that the average value and the median filter result in smoothing the measured potassium window count to $\sim 14$ count per readings, $F_{K U T}$ in Eq 3 . If these readings are smoothed, then applying the same methods to the window reading while the tool is in motion should reduce the noise $\mathrm{N}$ in Eq 3 making lithology changes more apparent.

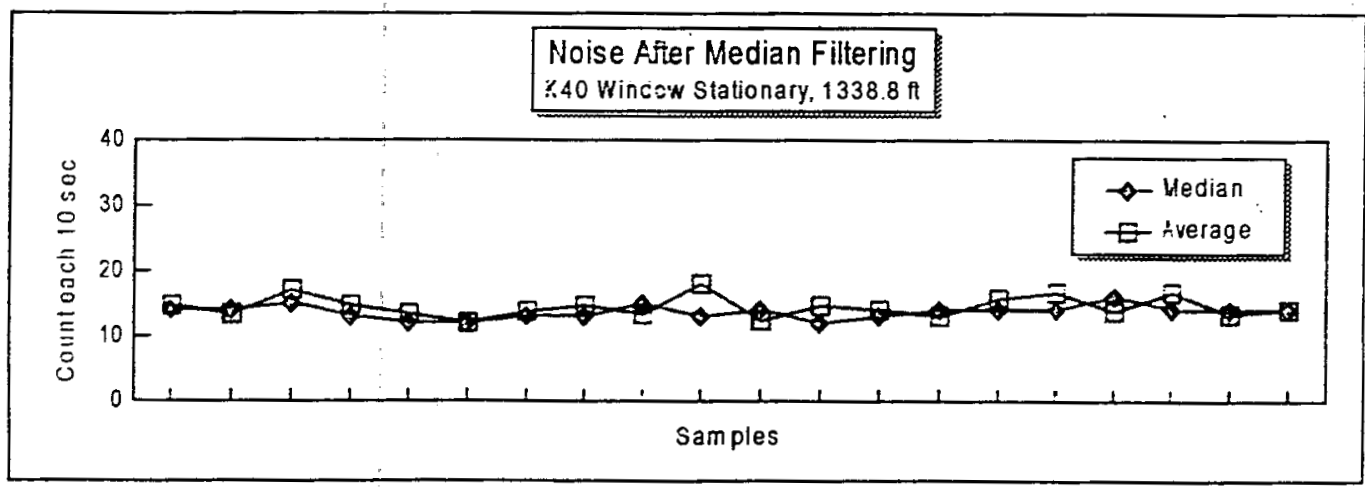

Figure 5. The median filter of the stationary gamma readings compared to taking the simple average.

The results of the three point median filter and the simple averaging of the three passes are shown in Figures 7 and 8, respectively. These resulted in a single set of readings for the $50 \mathrm{ft}$ well section. For 
completeness, Figure 6 shows the interim process of the median filter across each individual pass. The result shown in Figure 7 is the median value for each depth given the three passes in Figure 6. By filtering each pass first and then the ensemble, every point was compared to its neighbor in a two dimensional array.

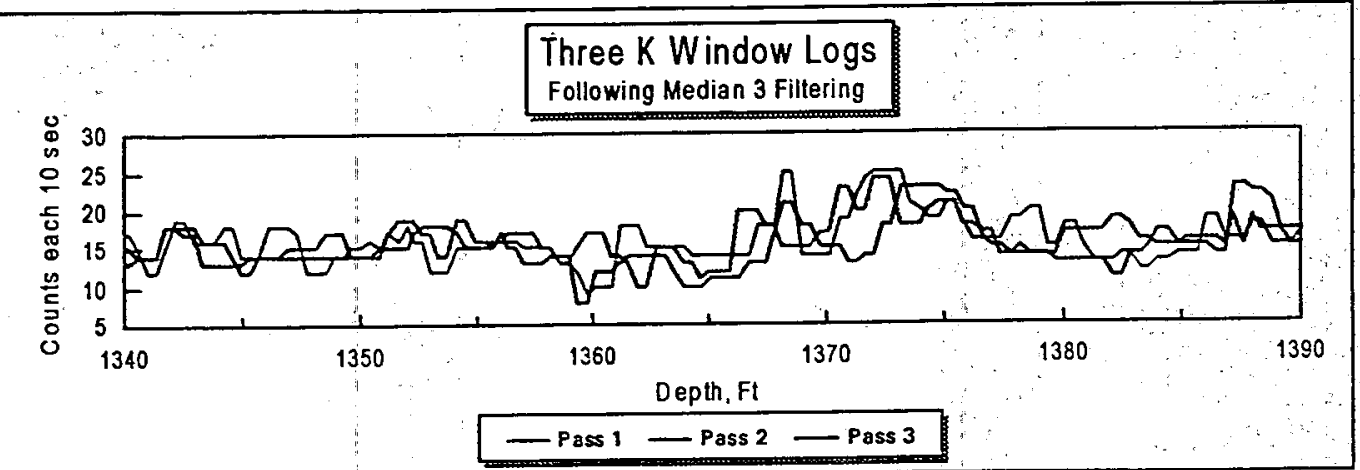

Figure 6. The median average for three points on each pass while logging at $2.25 \mathrm{ft} / \mathrm{min}$

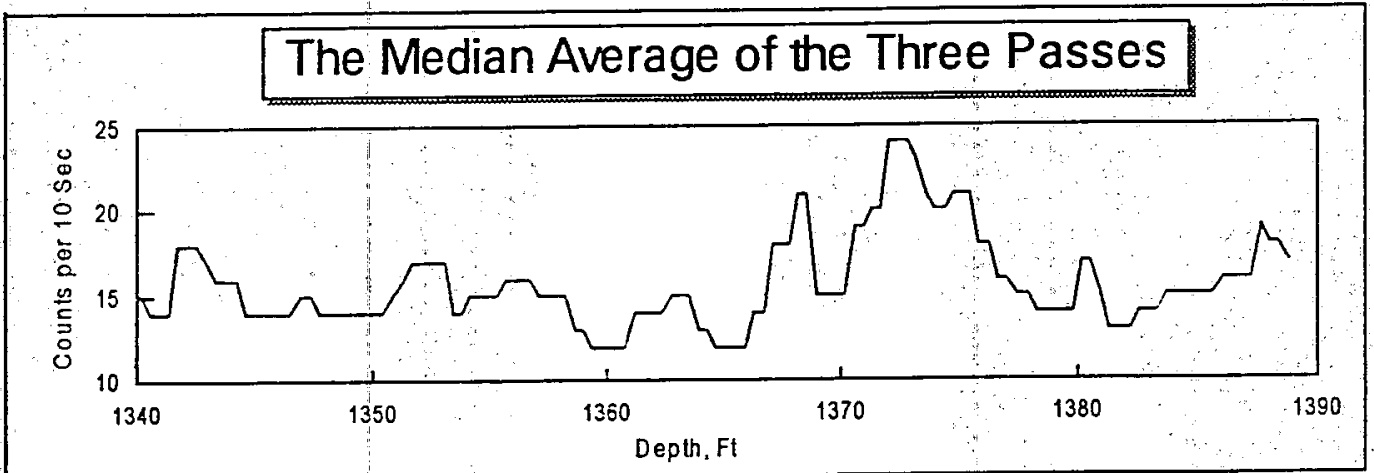

Figure 7. The median value of the three passes.

In Figure 7 the median filter reduces noise while preserving edges. Edges are important because they represent boundaries. The boundaries indicate formation changes or perhaps narrow veins of mineral deposits. More common linear filters or averaging restrict bandwidth to smooth signal readings. Reduced bandwidth rounds or smoothes edges. Another slight advantage of the median filter is that it smoothes signals while using actual readings. All of the data points in Figure 7 are actual potassium window count readings. For comparison, the three passes were filtered using a three point moving average, shown in Figure 8. Again, each signal was moving averaged and then the ensemble. One major limitation to ensemble filtering is the cost of increased logging time. Few well owners want to log multiple passes to gain one set of readings. For single pass measurements a Kalman filter was used

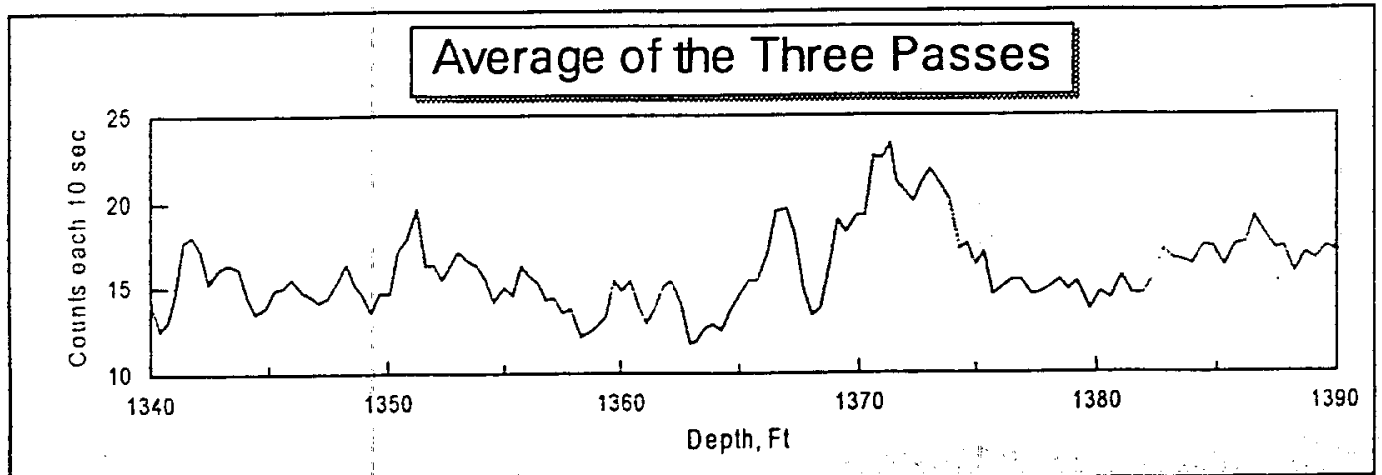

Figure 8. Using a three point moving average to filter the three passes. 


\section{Kalman Filter for Spectral Filtering}

Recursive digital filters based on estimators as Wiener and Kalman provide filtering through a statistical sense. The Kalman filter is well suited for filtering noisy measurements where both the noise and well lithology variances are known. For gamma count measurements, the standard deviation is equal to the square root of the expected value, Eq 4. For the stationary measurements at $1338.8 \mathrm{ft}$, the mean was 14.4 counts per period and the standard deviation is 3.8 counts per period. The standard deviation calculation is valid if the windowed count rate over the sample period is greater than five. At five and belon; the count rate fails to look Gaussian and is, instead, Poisson, [4].

The variance of the well lithology is now needed. This is the unknown random variable discussed earlier. Ruckebusch [4] suggests a well model which assumes slowly varying well lithology with an occasional jump to an unknown value. These jumps are at the formation boundaries.

$$
\begin{aligned}
& \text { Counting Variance (Noise): } \sigma_{K, U, T}=\sqrt{\mathrm{E}[\text { Window Count }]} \\
& \text { Well Model: } \mathrm{E}\left[\mathrm{KUT}_{\mathrm{n}+1}\right]=\mathrm{E}\left[\mathrm{KUT}_{\overline{2}}\right]+\varepsilon+\delta_{\mathrm{n}} \\
& \text { Kalman Error: } \mathrm{K}_{\mathrm{e}}=\mathrm{KUT}_{\mathrm{n} \div 1}-\mathrm{E}\left[\mathrm{KUT}_{\mathrm{n} \div 1}\right]
\end{aligned}
$$

Equation 4 is the assumed standard deviation taken as the square root of the estimated count mean. This is the noise variance used in the Kalman filter. Equation 5 models well lithology as a sequence of gamma Kalman estimates for KUT, E[KUT]. The estimate is assumed constant with exception of a small errors $\varepsilon$ and jump $\delta_{\mathrm{n}}$ at unknown points within the sequence (lithology changes). The sequence is $\mathrm{n}$ samples which correlates to depth within the well. To account for small changes in the well lithology a small error, $\varepsilon$,value is assumed based on priori information. Because of limited spectral log data in geothermal fields; $\varepsilon$ is a best guess at this time.

Now that the formal issues have been addressed, a simple explanation of the Kalman filter is in order. First, the filter will require establishing an estimated count rate mean for each of the KUT windoris. This is done by holding the tool stationary at any point, even within the logging truck. The stationary time should be greater than $5 \mathrm{~min}$, or long enough to let the tool's internal temperature stabilize. The value for $\varepsilon$ is preprogrammed. This value lets the filter follow slow changing lithology while not letting the filter react to transients. This clamping of the Kalman filter enforces well log repeatability. If the response is slowed then only major, hard-to-miss lithology changes are reported in the log.

Now that data is coming into the filter, the logging process begins. With each new measurement, the Kalman filter calculates its error, $\mathrm{K}_{\mathrm{e}}$. Here Equation 6 is taking the difference between the measured value and its estimated mean value. If the difference is less than three times $\sigma_{k u t}$, the filter assumes a valid estimate and moves its next estimated mean value only slighty; by a factor of $\varepsilon$. In short, if the measured value falls within the Gaussian distribution of the Kalman estimated gamma mean count rate; The Kalman estimated mean is kept with little change.

This process continues holding the filtered output centered within the statistical center of the readings. When a lithology changes quickly, the Kalman error is great. This is detected when the Kalman error, $\mathrm{K}_{\mathrm{e}}$ is more than three times $\sigma_{\mathrm{kut}}$. The Kalman filter can no longer use its estimated mean value. There are several published methods on how to generate a new estimated mean while logging. The Sandia method takes advantage of the fact that all data samples are stored in memory. We simply start a new value by jumping ahead eleven samples and calculating the Kalman estimated mean moving backwards though the measured data. This method was first presented by Fraser and Potter [7] in 1969. 


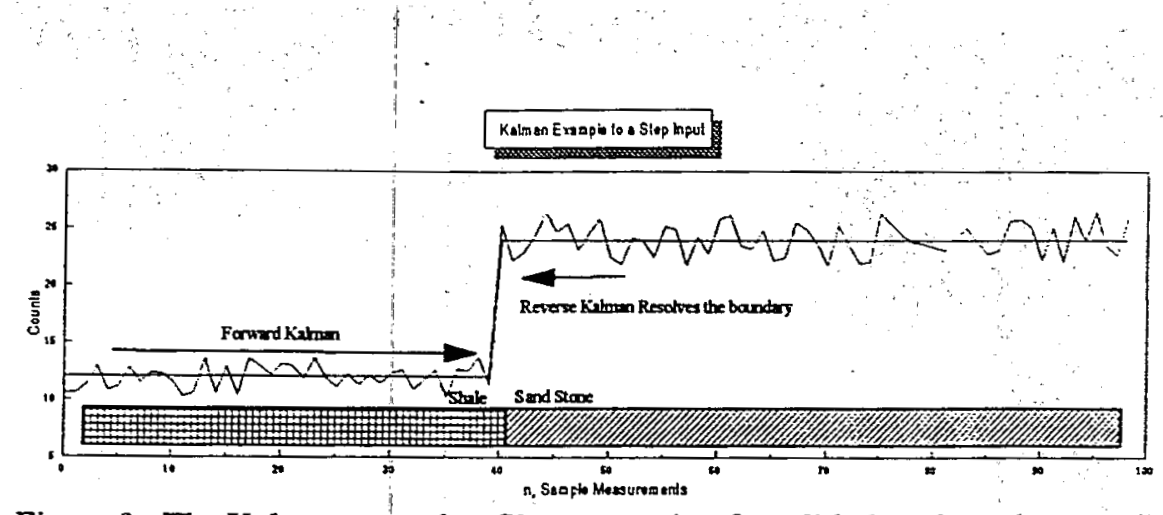

Figure 9. The Kalman smoother filter correcting for a lithology boundary condition.

By working backwards, the filter smoothes out gamma readings but allows for detection of abrupt boundary conditions, see Figure 9. Starting back some 11 samples improves the filter rejection of formation widths which are too small to be repeatable subsequent log runs.

Using the data from the test well, the Kalman filter is applied to a single pass while logging at $5 \mathrm{ft} / \mathrm{min}$. This rate does not provide the resolution of the three pass $2.25 \mathrm{ft} / \mathrm{min}$, but the similarities of the two measurements are better than should normally be expected. The Sandia tool under present design (crystal. size) should be logged at slower rates. The results are shown in Figures 10-13. Figure 10 contains the Kalman filtered values along with the actual potassium nindow counts. These data plots were produced by the Sandia tool software and copied into this Word ${ }^{\mathrm{TM}}$ document. This software was not arailable at the time the $\log$ was performed. This software is not fully developed and requires additional testing.

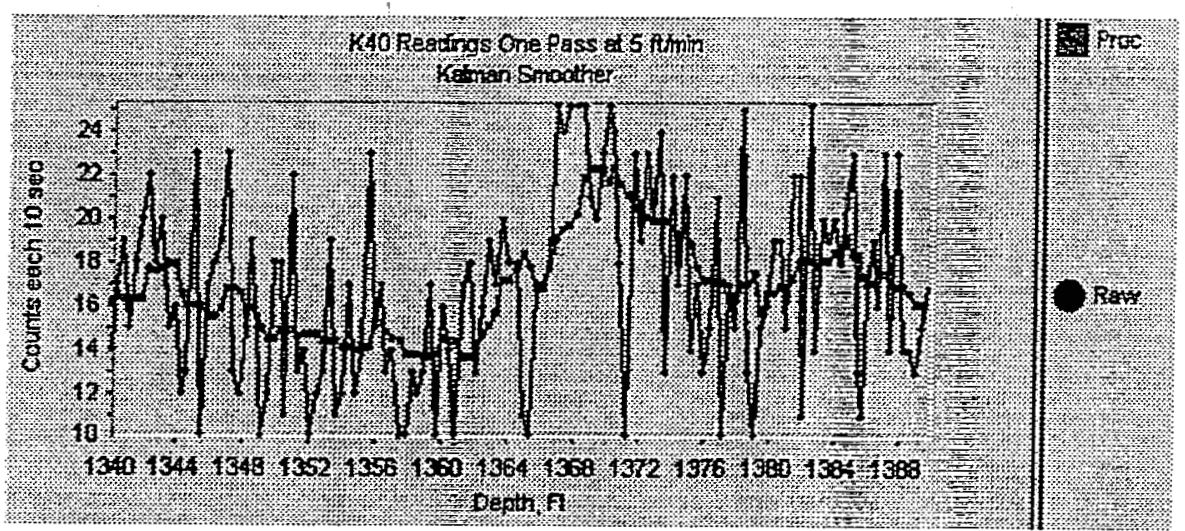

Figure 10. 50ft well section showing measured signal (blue, round) and Kalman filter response.

Figures 11-13 show the complete $160 \mathrm{ft}$ run for all three windors following the Kalman filter.

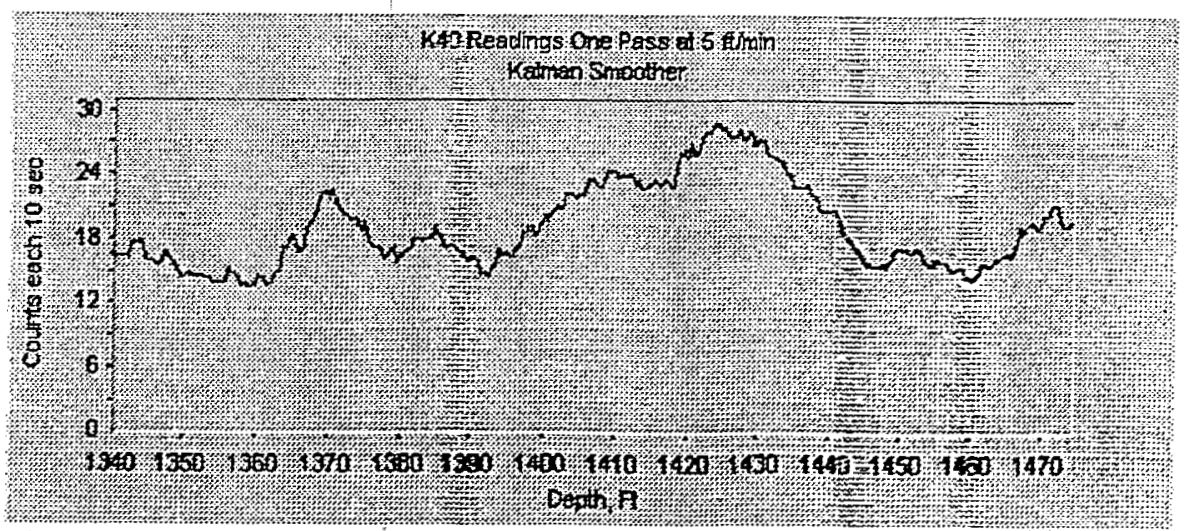

Figure 11. The complete $160 \mathrm{ft} \log$ showing potassium window counts. 


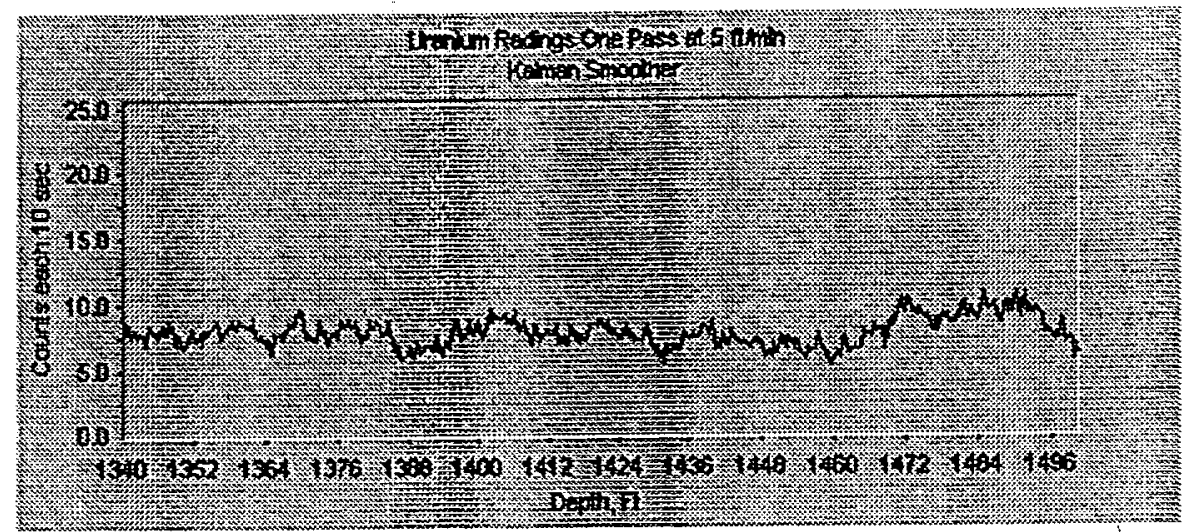

Figure 12. The complete $160 \mathrm{ft}$ log showing uranium window counts.

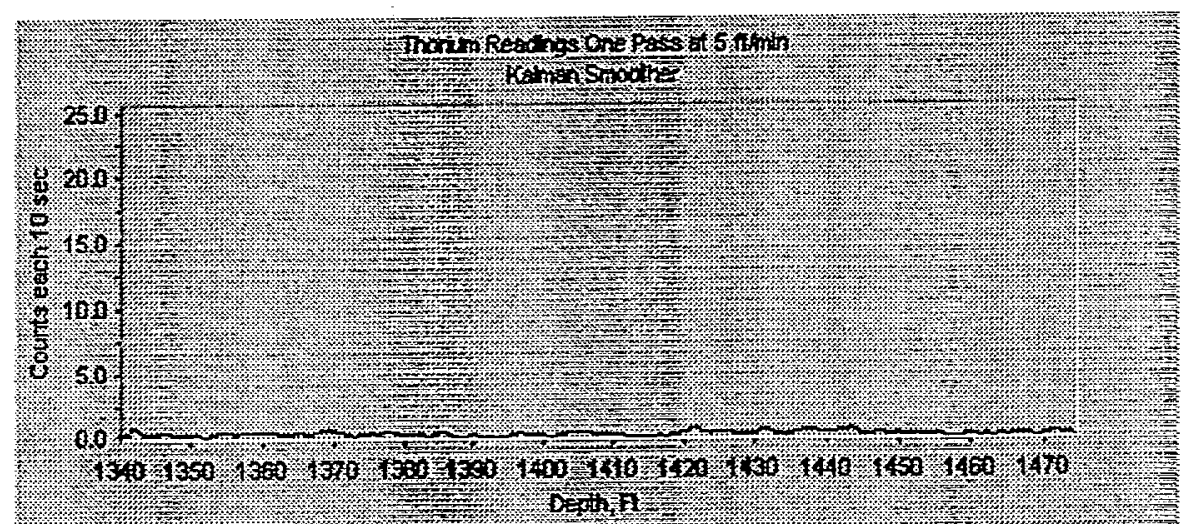

Figure 13. The complete $160 \mathrm{ft} \log$ showing the thorium window counts.

For window count readings within Figures 11 and 12 there are sufficient gamma counts to assume a Gaussian distribution. For Figure 13, the count rate was below an average of 5 . There are insufficient gamma counts to assume a Gaussian distribution with the standard variance of Equation 4 . Here the Kalman filter assumed a fixed variance giving the algorithm room to detect changes in count levels. The zero reading for the Thorium sindow indicates that the Thorium in the formation is well below that of the potassium.

\section{Conclusion}

The Sandia spectral tool is capable of tracking potassium within uncased small diameter well bores. The detector is also well suited for gamma logs in API units while also measuring the gamma spectrum. Commercial spectral logging tools commonly use 2 X8 and 2 X12 crystals. These crystals provide a gamma count rate 8 to 12 times greater than the 1 X6 used by the present slim hole spectral gamma tool. A second Sandia tool is being built using a $1.5 \times 6$ inch detector, which will increase the gamma coun rate three times.

Slight changes in KUT lithology readings within the well are hidden by the large variance of gamma count readings. The natural variance in gamma count readings is large due to the small sample period needed for locating formation boundaries. Two methods for reducing gamma count variance were explored. One was the ensemble median filter and the other Kalman filter. The ensemble median fitrer provides excellent spatial resolution at the cost of multiple logging runs over the same well sections. Because ensemble filtering is not practical for consumer logging, the Kalman filter was also explored Although the Kalman gave close representative readings to the ensemble, more filter testing is 
recommended. More testing mill lead to improvements in filter parameters, preserving spectral information that is most important to geothermal scientists and geologists.

\section{Acknowledgments}

Sandia is a multiprogram laboratory operated by Sandia Corporation, a Lockheed Martin Company, for the United States Department of Energy under contract DE-ACO4-94AL85000.

\section{References}

[1] M. Hassan and A. Hessin - Contribution àl etude des comportements du thorium et du potassium dans les roches sedimintaires" C.R. Acad Sci., France, Vol. 280. pp. $\$ 33-535,1975$

[2] J.A.S. Adams and C. E. Weaver: "Thorium to uranium ratios as indications of sedimentary processes: Example of concea of geochemical facies," Bull. Amer. Assoc. Petrol.Geol., vol. 42, pp 387-430, 1958

[3] David C. Stromsold and Robert D. Nilson. 'Calibration and Data Correction Tectmiques For Spectral Gamma-Ray Logging'. June 23 26, 81. SPWLA Twentr-Second Innuaj Logging Simposium

[4] Guy Ruckebusch, A Kalman Fihtring Approach to Natural Gamma Ray Spectrosiopy in Well Logging. IEEE Trans. on Auromatic Control, vol. ac-28,no.3, March 1983

[5] R. Leino, D.C. George, B.X. Key, L Knight, and W.D. Stzele, June 1994, Third Edition, Field Calibration Facilities for Envirommental Measurument of Radium. Thorium, and Potassium, technical Measurements Center Grand Junction Projects Office

[6] Russel Randall and David Stronswodd, Procedures for Calibrating Scintillation gamma-Ray. Well Logging Tools Using Formation Models, Int. Report RHC-SD-EN-TT-293, Fєb. 8, 1995

[7] Fraser, D.C. and Potter, J.E. "The Optimum Linear Smoother as a Combination of Two Optimum Linear Filters," IEEE Trans. On Auto. Control, AC-14:No. 4, 387, Augus 1969.

DISCLAIMER
This report was prepared as an account of work sponsored by an agency of the United States
Government. Neither the United States Gnvernment nor any agency thereof, nor any of their
employees, makes any warranty, express or implied, or assumes any legal liability or responsi-
bility for the accuracy, completeness, or usefulness of any information, apparatus, product, or
process disclosed, or represents that its use would not infringe privately owned rights. Refer-
ence herein to any specific commercial product; process, or service by trade name, trademark,
manufacturer, or otherwise does not necessarily constitute or imply its endorsement, recom-
mendation, or favoring by the United States Government or any agency thereof. The views
and opinions of authors expressed herein do not necessarily state or reflect those of the
United States Government or any agency thereof.

